Cite this article as: BMJ, doi:10.1136/bmj.38720.687975.55 (published 20 January 2006)

Research

\title{
Mobile phone use and risk of glioma in adults: case-control study
}

\author{
Sarah J Hepworth, Minouk J Schoemaker, Kenneth R Muir, Anthony J Swerdlow, Martie J A van Tongeren, Patricia A
} McKinney

\begin{abstract}
Objective To investigate the risk of glioma in adults in relation to mobile phone use.

Design Population based case-control study with collection of personal interview data.

Setting Five areas of the United Kingdom.

Participants 966 people aged 18 to 69 years diagnosed with a glioma from 1 December 2000 to 29 February 2004 and 1716 controls randomly selected from general practitioner lists.

Main outcome measures Odds ratios for risk of glioma in relation to mobile phone use.

Results The overall odds ratio for regular phone use was 0.94 (95\% confidence interval 0.78 to 1.13 ). There was no relation for risk of glioma and time since first use, lifetime years of use, and cumulative number of calls and hours of use. A significant excess risk for reported phone use ipsilateral to the tumour $(1.24,1.02$ to 1.52$)$ was paralleled by a significant reduction in risk $(0.75,0.61$ to 0.93$)$ for contralateral use.

Conclusions Use of a mobile phone, either in the short or medium term, is not associated with an increased risk of glioma. This is consistent with most but not all published studies. The complementary positive and negative risks associated with ipsilateral and contralateral use of the phone in relation to the side of the tumour might be due to recall bias.
\end{abstract}

\section{Introduction}

Gliomas are the most common malignancy of the central nervous system in adults, and the prognosis is extremely poor. ${ }^{1}$ The distinct histopathology and cellular origin of gliomas are probably associated with different aetiological pathways and mechanisms of carcinogenesis than other subtypes of brain tumours; the aetiology of gliomas, however, remains unclear. Recently, considerable interest has focused on whether the use of mobile phones is associated with an increased risk of gliomas and other brain tumours, even though little is known about potential mechanisms. ${ }^{2}$ The energy of the radiofrequency fields emitted by mobile phones is thought to be insufficient to cause malignant transformation through direct damage to DNA. ${ }^{3}$

Most published epidemiological studies on mobile phone use and gliomas have not generally reported any increased risk either overall or with long term use. ${ }^{4-7}$ Individual studies have found positive associations between high grade astrocytoma (glioma) and phone use ipsilateral to the side of the tumour, ${ }^{8}$ brain tumours and phone use in rural areas, ${ }^{9}$ and use of analogue mobile phones. ${ }^{8} 10$

We carried out a large population based case-control study of 966 patients with glioma in the United Kingdom. This study is part of the Interphone project, ${ }^{11}$ an international collaboration of 13 countries investigating mobile phone use and the risk of intracranial tumours.

\section{Methods and participants}

The study took place in the Thames regions of south east England and four areas to the north (Trent, West Midlands, West Yorkshire, and southern Scotland). The total catchment population (28.4 million) comprised $48.3 \%$ of the UK population. All areas followed a common protocol, with identical methods of case ascertainment and data collection with controls randomly sampled from general practitioner lists. The south east slightly differed in its method of control selection and the age range covered.

Cases were ascertained from multiple sources, including hospital departments (neurosurgery, neuro-oncology, neuropathology, neuroradiology, neurology) and cancer registries. Patients aged 18-69 years (northern centres) or 18-59 years (south east) lived in the study areas and had a first diagnosis between 1 December 2000 and 30 June 2003 (northern) or 29 February 2004 (south east) with a glioma (ICD-O-3 (international classification of diseases for oncology) ${ }^{12}$ topography: C71, morphology: 9380-9411, 9420-9460, 9480, 9505). Data on site, laterality (left, right, central) and grade of tumour (WHO grade high III-IV; low $\mathrm{I}-\mathrm{II}^{13}$ ) were abstracted from scan and pathology reports.

In the most recent year we have published data for (1992) an estimated $98 \%$ of the UK population was registered with a general practitioner. ${ }^{14}$ Controls were randomly selected from general practitioners' lists by a preset algorithm. In the south east the controls were frequency matched to reflect the age, sex, and geographical distribution of cases. In the northern centres one control per case was individually matched on age, sex, and general practice after the patient with glioma was interviewed. Nonparticipating controls were replaced. Parallel case-control studies of meningioma, acoustic neuroma, and other brain tumours were carried out with identical methods and questionnaires; the controls for these cases were included in the present analyses.

Consultants or general practitioners approached eligible participants personally or by an invitation letter. The study was introduced as an investigation of risk factors for brain tumours, without emphasising mobile phones. With the participant's informed consent, trained interviewers conducted a computer assisted personal interview. For 69 patients with glioma (7\%), interviewers conducted proxy interviews, mainly with spouses.

During the interview, if participants reported that they had ever made one or more calls each week on average for a period of six months or longer, they were asked a detailed set of questions on mobile phone use. For such participants, all makes and models of phone were recorded, with a comprehensive rep- 
ertoire of photographs to prompt recall. For each phone, the interviewer recorded the network operator, start and stop year, and the number and duration of calls made and received. If participants were uncertain about the calendar years or amount of use, a range was reported with the mean value taken for analysis. Additional details were gathered on which side of the head the phone was mostly used (50\% or more of the time) and factors influencing emitted power levels to the head, including use of hands-free kits (start and stop dates of use and proportion of time used) and whether the phone was used mainly in an urban or rural area or equally in both. ${ }^{15}$

In the analysis, we defined regular phone use as use for at least six months in the period more than a year before diagnosis. We defined diagnostic date as the date of diagnostic pathology $(n=935,97 \%)$ or date of the first diagnostic scan $(n=31,3 \%)$ if diagnostic pathology was unavailable. We assessed exposure to mobile phones using the number of years from first regular use of a phone until diagnosis or equivalent reference date for controls, lifetime years of regular use, lifetime cumulative use (hours), and lifetime cumulative number of calls. Long term users ( $>10$ years) were dichotomised into heavy ( $\geq 113$ hours) and light $(<113$ hours) cumulative hours of use in the period 10 or more years before diagnosis, with the cut off point based on the median hours of use among control participants. We used data collated by Interphone ${ }^{11}$ to classify phones as either analogue or digital, based on make and model of phone, year of use, and network operator capabilities during that period.

The exposure period for people with glioma was calculated up to a year before the date of diagnosis. An equivalent reference date was required for control participants that allowed for the increase in mobile phone use over the study period and as controls tended to be interviewed after the patients with glioma. For each area (south east, northern), we constructed case strata by single calendar year of interview and single year interval between diagnosis and interview ("interview lag time"). Control participants interviewed in each calendar year were randomly allocated to strata of interview lag time, proportionally to the distribution of the cases in the same calendar year, to obtain a similar distribution of lag time as in the cases. We then calculated the reference dates for controls by subtracting the mean interview lag time in cases in that stratum from the interview dates of the controls. Exposure indices were calculated up to a year before this reference date for controls (that is, a one year latency time was used). Additional analyses were carried out with a five year latency time.

\section{Statistical analysis}

For statistical analysis we used unconditional logistic regression (StataCorp, College Station, TX) adjusted for nine regions (five regions within the south east and the four northern regions), age at reference date (five year categories), sex, deprivation $\left(\right.$ Townsend score ${ }^{16}$ ), and combinations of interview year and lag time to account for the fact that controls were, on average, interviewed later in the study period than patients with glioma. We derived odds ratios for cumulative use with and without modification for reported use of headsets or hands-free sets in a vehicle, or both, ${ }^{717}$ with and without proxy case interviews, and separately for high and low grade tumours and urban versus rural use. We also performed a conditional logistic regression analysis on the matched northern case-control dataset.

We used two methods to assess the risk of a tumour ipsilateral or contralateral to side of phone use. Firstly, we took two groups of patients with right and left sided tumours ${ }^{17}$ and randomly assigned controls to each group and considered them to have a tumour on that side (50\% left, $50 \%$ right) for the analysis. The odds ratio for risk of an ipsilateral tumour was based on the results of a logistic regression analysis where ipsilateral phone use was use on the same side of the head as the tumour for cases or the assigned side for controls. We adjusted the analysis for the side of the tumour as well as the variables adjusted for in the main analysis. If the phone was used on the opposite side to the side of tumour/allocated side the participant was classified as unexposed. Those who reported using the phone on both sides of the head were considered exposed on both the left and right sides. ${ }^{6}{ }^{17}$ As the allocation of controls was based on a random assignment, the logistic regression analysis was repeated 500 times; the results for the analysis that gave the median odds ratio for ipsilateral regular phone use are presented. A similar analysis of contralateral use (use on the opposite side of the head to the tumour or allocated side) was performed. The second method calculates a relative risk for laterality of reported side of use in relation to tumour laterality but only in cases. ${ }^{4}$

\section{Results}

Researchers interviewed 966 cases (367 in the south east and 599 in northern areas) and 1716 controls (630 and 1086). The main reasons for non-participation were the participant was too ill or had died before interview (cases 30\%, controls $<1 \%$ ), nonresponse (cases 2\%, controls 21\%), refusal (cases 10\%, controls $29 \%$ ), and other reasons (refusal by consultant or general practitioner, non-English speaking, mental impairment) (cases 7\%, controls 5\%). Non-responders included those for whom contact details may have been incorrect. Overall response rates were 51\% for patients with glioma and $45 \%$ for controls, representing the proportion of all eligible cases and controls from the study areas who were interviewed in the study. Exclusion of the non-responders (that is, who may never actually have been asked) gave response rates of $51 \%$ and $57 \%$. Interviewed patients with glioma were broadly representative of the overall set of those eligible by age and sex but differed by deprivation category, being significantly more affluent $\left(\chi^{2}\right.$ test for trend, $\mathrm{P}<0.001)$. People with low grade glioma were significantly more likely to be interviewed $\left(\chi^{2}\right.$ test, $\left.\mathrm{P}<0.001\right)$ than those with high grade glioma. For control participants, those interviewed were more likely to be women $\left(\chi^{2}\right.$ test, $\left.\mathrm{P}<0.001\right)$ and more likely to be affluent $\left(\chi^{2}\right.$ test for trend, $\left.\mathrm{P}<0.001\right)$ than those who were not interviewed.

Table 1 shows the demographic distribution of interviewed cases and controls. The proportion of men was higher among the patients with glioma than in the control group. There was also a slight tendency for interviewed controls to live in more affluent areas than interviewed patients with glioma.

Table 2 shows an odds ratio of 0.94 (95\% confidence interval 0.78 to 1.13 ) for regular phone users compared with those who never or only occasionally used mobile phones. There was no association of risk with lifetime years of use, cumulative hours of use, cumulative numbers of calls, nor cumulative hours of use over 10 years before the reference date. These findings were similar after we excluded patients with glioma with proxy interviews $(n=69)$, adjusted cumulative hours of phone use and number of calls for use of hands-free kits, applied a five year lag time, or restricted analysis to matched case-control analysis of northern cases. Table 2 also shows no significant associations with use in urban or rural areas or separately for 650 high grade and 306 low grade gliomas.

We found a significant odds ratio of 1.24 (1.02 to 1.52) for a tumour ipsilateral to side of phone use and a reduced odds ratio 
Research

Table 1 Demographic distributions in cases and controls. Figures are numbers (percentages) of participants

Cases $(n=966) \quad$ Controls $(n=1716)$

\begin{tabular}{lcc}
\hline & & \\
\hline Region: & $367(38.0)$ & $630(36.7)$ \\
\hline Thames regions & $152(15.7)$ & $277(16.1)$ \\
\hline Southern Scotland & $199(20.6)$ & $372(21.7)$ \\
\hline Trent & $115(11.9)$ & $207(12.1)$ \\
\hline West Midlands & $133(13.8)$ & $230(13.4)$ \\
\hline West Yorkshire & & $112(6.5)$ \\
\hline Age at reference date (years): & $100(10.4)$ & $281(16.4)$ \\
\hline $18-29$ & $199(20.6)$ & $429(25.0)$ \\
\hline $30-39$ & $216(22.4)$ & $645(37.6)$ \\
\hline $40-49$ & $328(34.0)$ & $249(14.5)$ \\
\hline $50-59$ & $123(12.7)$ & $829(48.3)$ \\
\hline $60-69 \dagger$ & $604(62.5)$ & $887(51.7)$ \\
\hline Men & $362(37.5)$ & $513(29.9)$ \\
\hline Women & & $386(22.5)$ \\
\hline Deprivation score* & $257(26.6)$ & $334(19.5)$ \\
\hline 1 (most affluent) & $229(23.7)$ & $292(17.0)$ \\
\hline 2 & $178(18.4)$ & $191(11.1)$ \\
\hline 3 & $181(18.7)$ & \\
\hline 4 & $121(12.5)$ & \\
\hline 5 (least affluent) &
\end{tabular}

*Townsend score (area based measure of deprivation) categorised into five equally sized groups based on 2001 census data.

†In control group includes seven people aged $>69$ at reference date.

for contralateral use $(0.75,0.61$ to 0.93$)$ (table 2$)$. Similar respective excesses and deficits were present for all exposure measures of mobile phone use, including use for $\geq 10$ years (ipsilateral $1.60,0.92$ to 2.76 ; contralateral $0.78,0.43$ to 1.41 ). To investigate this further, we analysed regular use ipsilateral and contralateral to handedness, which gave odds ratios of 0.78 (0.62 to 0.99$)$ and 1.07 (0.85 to 1.35 ), respectively. The concordance between reported side of use and handedness was $59 \%$ for cases and $64 \%$ among controls. The method of Inskip et $\mathrm{al}^{4}$ gave an overall relative risk of 1.3 (Fisher's exact $\mathrm{P}<0.001$ ) for a tumour ipsilateral to the side of phone use.

We examined use of analogue phones separately but there were no significant odds ratios with any exposure metric (table 3). Results from the conditional regression analysis of matched data from the northern centres did not differ from the overall findings.

\section{Discussion}

This large study on associations between mobile phone use and the risk of developing a glioma in a UK population has nearly twice as many cases as the largest previously reported studies of gliomas, ${ }^{45}$ with more long term users. In addition, it was designed specifically to address exposure to mobile phones, with comprehensive and relevant collection of data. Overall, we found no raised risk of glioma associated with regular mobile phone use and no association with time since first use, lifetime years of use, cumulative hours of use, or number of calls. Our results are consistent with findings from investigations of mobile phone use in the US, ${ }^{45}$ Denmark, ${ }^{78}$ and Sweden, ${ }^{6}$ though some studies have found isolated positive associations for particular variables. $^{8-10}$

Analogue phones emit higher average power levels than digital phones. ${ }^{19}$ If mobile phone use was causally linked to the development of glioma and risk was related to power level, we would predict a higher risk for analogue phone use than for digital phones. As in some ${ }^{6718}$ but not all ${ }^{810}$ previous reports we found no association between risk of glioma and use of analogue
Table 2 Odds ratios and 95\% confidence intervals for risk of glioma in relation to mobile phone exposure* ${ }^{*}$ Figures are numbers (percentages) of participants

\begin{tabular}{|c|c|c|c|c|}
\hline Factor and level of exposure & Cases & $(n=966)$ & $\begin{array}{l}\text { Controls } \\
(\mathrm{n}=1716)\end{array}$ & Odds ratio† $(95 \% \mathrm{CI})$ \\
\hline \multicolumn{5}{|l|}{ Frequency of use: } \\
\hline Never/non-regular & 456 & $(47.2)$ & $818(47.7)$ & 1.00 \\
\hline Regular & 508 & $(52.6)$ & $898(52.3)$ & 0.94 (0.78 to 1.13$)$ \\
\hline Not known & & $(0.2)$ & 0 & - \\
\hline \multicolumn{5}{|l|}{ Years since first use: } \\
\hline Never/non-regular & 456 & $(47.2)$ & $818(47.7)$ & 1.00 \\
\hline $1.5-4 \ddagger$ & 271 & $(28.1)$ & $515(30.0)$ & 0.90 (0.73 to 1.11$)$ \\
\hline $5-9$ & 170 & $(17.6)$ & $270(15.7)$ & 1.04 (0.80 to 1.34$)$ \\
\hline$\geq 10$ & 66 & $(6.8)$ & $112(6.5)$ & 0.90 (0.63 to 1.28$)$ \\
\hline Not known & 3 & $(0.3)$ & $1(0.1)$ & - \\
\hline \multicolumn{5}{|l|}{ Lifetime years of use: } \\
\hline Never/non-regular & 456 & $(47.2)$ & $818(47.7)$ & 1.00 \\
\hline $0.5-4$ & 342 & $(35.4)$ & $623(36.3)$ & 0.93 (0.76 to 1.14$)$ \\
\hline $5-9$ & 115 & $(11.9)$ & $206(12.0)$ & 0.88 (0.66 to 1.17$)$ \\
\hline$\geq 10$ & 48 & $(5.0)$ & $67(3.9)$ & 1.14 (0.74 to 1.73$)$ \\
\hline Not known & 5 & $(0.5)$ & $2(0.1)$ & - \\
\hline \multicolumn{5}{|l|}{ Cumulative hours of use§: } \\
\hline Never/non-regular & 456 & $(47.2)$ & $818(47.7)$ & 1.00 \\
\hline$\leq 99$ & 225 & $(23.3)$ & $444(25.9)$ & 0.94 (0.76 to 1.17$)$ \\
\hline $99-\leq 544$ & 128 & $(13.3)$ & $218(12.7)$ & 0.87 (0.65 to 1.15$)$ \\
\hline$>544$ & 135 & $(14.0)$ & 217 (12.6) & 0.94 (0.71 to 1.23$)$ \\
\hline Not known & 22 & (2.3) & $19(1.1)$ & - \\
\hline \multicolumn{5}{|l|}{ Cumulative number of calls§: } \\
\hline Never/non-regular & 456 & $(47.2)$ & $818(47.7)$ & 1.00 \\
\hline$\leq 2071$ & 237 & $(24.7)$ & $444(25.9)$ & 0.99 (0.80 to 1.23$)$ \\
\hline $2071-\leq 6909$ & 102 & $(10.6)$ & $217(12.6)$ & 0.70 (0.52 to 0.93$)$ \\
\hline$>6909$ & 146 & (15.1) & $218(12.7)$ & 0.97 (0.74 to 1.28$)$ \\
\hline Not known & 25 & (2.6) & $19(1.1)$ & - \\
\hline
\end{tabular}

Cumulative hours of use $\geq 10$ years agon:

\begin{tabular}{lcrcc}
\hline Never/non-regular & $456(47.2)$ & $818(47.7)$ & 1.00 \\
\hline$<10$ years & $429(44.4)$ & $772(45.0)$ & $0.93(0.77$ to 1.13$)$ \\
\hline$\geq 10$ years, $\leq 113$ hours & $23(2.4)$ & $56(3.3)$ & $0.61(0.36$ to 1.04$)$ \\
\hline$\geq 10$ years, $>113$ hours & $39(4.0)$ & $54(3.2)$ & $1.11(0.70$ to 1.75$)$ \\
\hline Not known & $19(2.0)$ & $16(1.0)$ & - \\
\hline Proportion urban/rural at first use: & $456(47.2)$ & $818(47.7)$ & 1.00 \\
\hline Never/non-regular & $241(24.9)$ & $471(27.4)$ & $0.83(0.66$ to 1.03$)$ \\
\hline Mainly urban & $49(5.1)$ & $84(4.9)$ & $0.98(0.66$ to 1.46$)$ \\
\hline Mainly rural & $215(22.3)$ & $343(20.0)$ & $1.05(0.83$ to 1.31) \\
\hline Both & $5(0.5)$ & 0 & - \\
\hline Not known & & &
\end{tabular}

\section{According to tumour grade **}

Frequency of use in those with high grade tumours:

\begin{tabular}{lcccc}
\multicolumn{1}{l}{ Frequency of use in those with high grade tumours: } \\
\hline Never/non-regular & $331(50.9)$ & $818(47.7)$ & 1.00 \\
\hline Regular & $317(48.8)$ & 898 & $(52.3)$ & $0.95(0.77$ to 1.17) \\
\hline
\end{tabular}

Not known $2(0.3)$

Frequency of use in those with low grade tumours:

\begin{tabular}{lcccc}
\hline Frequency of use in those with low grade tumours: & & \\
\hline Never/non-regular & $122(39.9)$ & 818 & $(47.7)$ & 1.00 \\
\hline Regular & $184(60.1)$ & 898 & $(52.3)$ & $0.85(0.63$ to 1.13$)$ \\
\hline Not known & 0 & 0 & -
\end{tabular}

Not known

According to side of phone usett

Frequency of ipsilateral use ${ }^{*}$

\begin{tabular}{lcccc}
\hline Never/non-regular & $550(66.3)$ & $1230(71.7)$ & 1.00 \\
\hline Regular & $278(33.5)$ & $486(28.3)$ & $1.24(1.02$ to 1.52) \\
\hline Not known & $2(0.2)$ & 0 & - \\
\hline Frequency of contralateral use ${ }^{*}:$ & & & \\
\hline Never/non-regular & $629(75.8)$ & $1225(71.4)$ & 1.00 \\
\hline Regular & $199(24.0)$ & $491(28.6)$ & $0.75(0.61$ to 0.93$)$ \\
\hline Not known & $2(0.2)$ & 0 & -
\end{tabular}

* ${ }^{*}$ Reference category is never or non-regular use of any type of mobile phone and, in ipsilateral analysis, phone use only on opposite side of tumour, and in contralateral analysis, phone use only on same side as tumour.

tOdds ratios adjusted for age at reference date (in 5 year age groups), sex, region, Townsend †Odds ratios adjusted for age at reference date (in 5 year age
deprivation category, and interview reference date category. 
ҒLower limit 1.5 years ago because regular phone use defined as phone use of at least six months' duration at least one year before reference date.

$\S$ For cumulative number and duration of calls category cut-off points were median and 75 th centile of use for controls who were regular phone users.

IUse over 10 years before reference date for controls and diagnosis date for cases. **10 tumours $(1.7 \%)$ were of undetermined grade.

$t+\ln 449(46.5 \%)$ cases tumour was classified as being on right side of head and in 387

$(40.1 \%)$ on left side, 49 cases $(5.1 \%)$ were excluded from this analysis because tumour was central, 81 cases $(8.4 \%)$ because side of tumour was unknown, six others where side of phone use was unknown were also excluded.

phones overall or with time since first use, lifetime years of use, or cumulative hours or number of calls.

In Sweden Hardell et al reported raised risks for mobile phone use ipsilateral to the side of development of high grade astrocytomas (the principal subtype of glioma) ${ }^{8}$ and for rural use in different analyses of the same study. ${ }^{9}$ Several other studies, however, could not confirm these results and the methods were criticised. $^{32021}$ Our laterality analyses both showed a significantly raised risk for ipsilateral phone use. Using the methods of Lonn et al, ${ }^{17}$ however, we found a significantly reduced risk for contralateral use. These "complementary risks" above and below unity, which we observed for all measures of mobile phone use, can probably be explained by recall bias. ${ }^{21}$ The patients with glioma, who were aware of the location of their tumour, may have considered that mobile phone use was a cause of its development, resulting in systematically over-reporting of phone use on the side of the head where their cancer occurred. Generally, individuals are likely to overestimate their actual use of mobile phones, ${ }^{22}$ and this may have exaggerated the effect of differential reporting for laterality. To investigate this issue further, we made case-control comparisons by handedness as people tend to use the phone on their handed side and because

Table 3 Odds ratios and 95\% confidence intervals for risk of glioma in relation to use of analogue phones

\begin{tabular}{|c|c|c|c|}
\hline $\begin{array}{l}\text { Factor and level of } \\
\text { exposure }\end{array}$ & Cases & Controls & Odds ratio $(95 \% \mathrm{Cl})$ \\
\hline \multicolumn{4}{|l|}{ Frequency of use ${ }^{\star}$ : } \\
\hline Never/non-regular & $456(47.2)$ & $818(47.7)$ & 1.0 \\
\hline Digital only & 378 (39.1) & $685(39.9)$ & 0.96 (0.79 to 1.16$)$ \\
\hline Regular analogue & $128(13.3)$ & $212(12.4)$ & 0.87 (0.66 to 1.15$)$ \\
\hline Not known & $4(0.4)$ & $1(0.1)$ & - \\
\hline \multicolumn{4}{|l|}{ Years since first use: } \\
\hline Never/non-regular & $456(47.2)$ & $818(47.7)$ & 1.0 \\
\hline Digital only & $378(39.1)$ & $685(39.9)$ & 0.96 (0.79 to 1.16$)$ \\
\hline $1.5-4 \dagger$ & $15(1.6)$ & $33(1.9)$ & 0.59 (0.30 to 1.15) \\
\hline $5-9$ & $56(5.8)$ & $84(4.9)$ & 0.98 (0.66 to 1.45) \\
\hline$\geq 10$ & $56(5.8)$ & $95(5.5)$ & 0.87 (0.59 to 1.27) \\
\hline Not known & $5(0.5)$ & $1(0.1)$ & - \\
\hline \multicolumn{4}{|l|}{ Lifetime years of use: } \\
\hline Never/non-regular & $456(47.2)$ & $818(47.7)$ & 1.0 \\
\hline Digital only & $378(39.1)$ & $685(39.9)$ & 0.96 (0.79 to 1.16) \\
\hline $0.5-4$ & $90(9.3)$ & $159(9.3)$ & $0.82(0.60$ to 1.11$)$ \\
\hline $5-9$ & $27(2.8)$ & $42(2.4)$ & 0.97 (0.57 to 1.66) \\
\hline$\geq 10$ & $10(1.0)$ & $11(0.6)$ & 1.20 (0.48 to 3.04$)$ \\
\hline Not known & $5(0.5)$ & $1(0.1)$ & - \\
\hline \multicolumn{4}{|c|}{ Cumulative hours of use $\geq 10$ years agoł: } \\
\hline Never/non-regular & $456(47.2)$ & $818(47.7)$ & 1.0 \\
\hline Digital only & $378(39.1)$ & $685(39.9)$ & 0.95 (0.79 to 1.16$)$ \\
\hline$<10$ years & $69(7.1)$ & $115(6.7)$ & 0.86 (0.61 to 1.22) \\
\hline$\geq 10$ years, $\leq 126$ hours & $23(2.4)$ & $47(2.7)$ & 0.70 (0.41 to 1.21) \\
\hline$\geq 10$ years, $>126$ hours & $31(3.2)$ & $47(2.7)$ & 0.98 (0.59 to 1.62) \\
\hline Not known & $9(0.9)$ & $4(0.2)$ & - \\
\hline
\end{tabular}

${ }^{*}$ Of 4055 phones reported by participants, $586(14.5 \%)$ were analogue, $3183(78.5 \%)$ were digital, and $286(7.1 \%)$ could not be classified.

†Lower limit 1.5 years ago because regular phone use defined as phone use of at least six months' duration at least one year before reference date.

$\neq$ Use $\geq 10$ years before reference date for controls and diagnosis date for cases. handedness is a variable reported at interview and not likely to be subject to recall bias. The clear pattern of significant odds ratios above and below unity for ipsilateral and contralateral mobile phone use, respectively, was not seen for handedness in equivalent analyses.

\section{Potential bias}

Case-control studies are subject to certain biases and particularly participation bias. ${ }^{23}$ We interviewed $51 \%$ of those patients with glioma who were eligible, mainly because rapid death prevented us from approaching all of them. As early death is most likely in patients with high grade tumours, it is not surprising that participation rates were higher in those with low grade tumours. A bias in these results would occur only if mobile phone use was related to severity of tumour, which was not supported by our analysis, where odds ratios for mobile phone use showed no increased risk for high or low grade tumours.

There is also potential for the introduction of participation bias into the control group. All controls were selected to represent the general population by using the sampling frame of general practitioners' lists. Although methods varied between the south east and northern centres, the analysis strategy of frequency matching permitted a combined approach. The overall response rate for controls was relatively low (45\%) compared with previously published studies from the Nordic countries ${ }^{6} 7$ on mobile phone use and risk of glioma. Recruitment of controls was a complicated procedure, and we tried to optimise participation rates. Prevailing legislation on consent from patients made the process a resource intensive exercise for general practitioners and in some instances the study could not follow-up patients directly, instead relying on general practitioners to undertake this process. The principal reason for non-participation of controls was that they were "uncontactable," and constraints imposed by ethical approval bodies prevented more than one follow-up attempt. It is likely, therefore, that some of the apparent non-responders were in fact individuals who were never contacted and therefore had no opportunity to respond. Our interviewed controls were more affluent than their non-interviewed counterparts and the interviewed patients with glioma. Though we adjusted for deprivation in all the analyses, this cannot completely remove its potential influence.

There is generally a lack of convincing and consistent evidence of any effect of exposure to radiofrequency field on risk of cancer. ${ }^{24}{ }^{25}$ Overall our findings are consistent with this and with most studies on mobile phone use. The positive association found between risk of glioma and ipsilateral mobile phone use was accompanied by a negative association for the opposite side of use to the tumour. Although it is possible the ipsilateral association represents a real effect, this finding is probably explained by recall bias, with patients with glioma systematically over-reporting use on the same side as their tumour and consequently under-reporting use on the opposite side. This study suggests that there are no substantially raised risks of glioma in the 10 years after first mobile phone use. Only future studies will be able to address longer latency periods for the development of glioma.

We thank all the individuals who were interviewed for this project; all the study interviewers, administrators, and computer programmers who collected and processed the data; and Elisabeth Cardis, the coordinator of the Interphone study, and her colleagues for support and provision of data. The Northern UK study acknowledges the support of the membership of the study steering group chaired by David Coggon and the following neuropathologists, neuroradiologists, neurosurgeons, neuro-oncologists, clinical oncologists, neurologists, specialist nurses, and administrators based in hospitals located in Scotland (P Barlow, I Bone, J Brown, J Crowther, R 


\section{What is already known on this topic}

Gliomas are a specific type of brain tumour for which the causes are generally unknown, but concern has been expressed over a possible link with using a mobile phone

\section{What this study adds}

This large case-control study found no increased risk of developing a glioma associated with mobile phone use either in the short or medium term

Dolan, L Dunn, M O Fitzpatrick, M Fraser, R Grant, A Gregor, J Ironside, R Johnstone, K W Lyndsay, S Macnamara, J Mair, R Mills, L Myles, B O'Reilly, V Papanastassiou, R Rampling, M Russell, D Sim, P Statham, J Steers, W A Taylor, G Teasdale, I Whittle), West Midlands (J M Anderson, P Barber, C R Barraclough, P Bennett, H G Boddie, A Brind, P Carey, M Choksey, M Christie, R N Corston, G S Cruickshank, A Detta, P Dias, S J Ellis, G Flint, D A Francis, A H Grubneac, S P Harland, C Hawkins, T Heafield, R C Hughes, D G Jamieson, A Logan, C H A Meyer, R Mitchell, K Morrison, P Newman, D Nicholl, S Nightingale, H S Pall, J R Ponsford, A Shehu, J Singh, J A Spillane, P Stanworth, B Summers, A R Walsh, J Wasserberg, A C Williams, J Winer, S Zygmunt), Trent (R J Abbott, S Adams, R D Ashpole, R D E Battersby, L Blumhardt, P Byrne, M Cartmill, S C Coley, P Critchley, B B Faraj, A Gibson, P Griffiths, R Grunwald, TJ Hodgson, D T Hope, S Howell, D Jefferson, D Jelinek, N Jordan, A Kemeny, M C Lawden, J Lowe, N Messios, Kirsty Pardoe, S Price, I F Pye, M Radatz, I Robertson, K Robson, C Romanowski, G Sawle, B Sharrock, P Shaw, C Smith, W Temperley, G Venables, B White, A M Whiteley, AJ Wills), and West Yorkshire (A S N Al-Din, D Ash, J Bamford, M Bond, G Bonsor, L Bridges, B Carey, A Chakrabarty, P Chumas, D Dafalla, H Ford, G E Gerrard, P J Goulding, J Howe, S Jamieson, M H Johnson, L A Louizou, P Marks, M Nelson, S Omer, N Phillips, S Ross, I Rothwell, H Spokes, J Straiton, G Towns, A Tyagi, P Vanhille, M Busby).The Southeast England study thanks D Hogben for study administration and their research nurses, A Butlin, J Owens, A Hart, R Knight, C Parsley, M Pelerin, K Sampson and M Swanwick, for data collection. They thank $\mathrm{H}$ Møller, B Plewa, and S Richards from the Thames Cancer Registry and the following neuropathologists, neurosurgeons, neuro-oncologists, clinical oncologists, neurologists, administrators, and secretaries for the help they provided: D G Hardy, P J Kilpatrick, R Macfarlane (Addenbrooke's Hospital); M Cronin, T Foster, S Furey, M G Glaser, F Jones, N D Mendoza, E S Newlands, K S O'Neill, D Peterson, F Taylor, J van Dellon (Charing Cross Hospital); J J Bending (Eastbourne District Hospital); P R Bullock, C Chandler, B Chitnavis, L Doey, R W Gullan, C E Polkey, R Selway, M M Sharr, L Smith, A J Strong, N Thomas (King's College Hospital); G M Sadler (Maidstone Hospital); S Short (Mount Vernon Hospital); S Brandner, A D Cheesman, J P Grieve, W J Harkness, R Kapoor, N D Kitchen, T Pearce, M P Powell, J Rees, F Scaravilli, D T Thomas, L D Watkins (National Hospital for Neurology and Neurosurgery); A R Aspoas, S Bavetta, J C Benjamin, K M David, J R Pollock, E Sims (Oldchurch Hospital); J Armstrong, J Akinwunmi, G Critchley, L Gunasekera, C Hardwidge, J S Norris, P E Rose, P H Walter, P J Ward, M Wilkins (Princess Royal Hospital); T Z Aziz, D Kerr, P J Teddy (Radcliffe Infirmary); M Allen, T Dale, R Bradford, A P Dhillon, N L Dorward, D Farraday-Browne, D J McLaughlin, R S Maurice-Williams, K Pigott, B Reynolds, C Shah, C Shieff, E M Wilson (Royal Free Hospital); F Afshar, H E Ellamushi, P M Richardson, H I Sabin, J Wadley (Royal London Hospital); M Brada, F H Saran, D Traish (Royal Marsden Hospital); S Whitaker (Royal Surrey County Hospital); P N Plowman (St Bartholomew's Hospital); Carole Bramwell, A Bell, F Johnston, H Marsh, A Martin, P S Minhas, A Moore, S Stapleton, S Wilson (St George's Hospital); R P Beaney (St Thomas' Hospital).

Contributors: PAMcK, MJS, KRM, MJAvT, and AJS were responsible for the design and implementation of the study. SJH and MJS conducted the statistical analysis. PAMcK and SJH wrote the first draft of the paper. All coauthors provided comments on the draft. PAMcK is the guarantor.

Funding: The south east and northern UK studies received funding from the Mobile Telecommunications, Health and Research (MTHR) programme and as part of the Interphone study from the EU, the Mobile Manufacturers Forum, and the GSM Association through the scientifically independent Union Internationale Contre le Cancer (UICC). In addition the northern UK study received funding from the Health and Safety Executive, the Department of Health, the UK network operators $\left(\mathrm{O}_{2}\right.$, Orange, T-Mobile, Vodafone, 3), and the Scottish Executive.
Competing interest: The University of Leeds has received some financial support on behalf of the four centres of the UK northern study from the UK network operators $\left(\mathrm{O}_{2}\right.$, Orange, T-Mobile, Vodafone, 3) under legal signed contractual agreements which ensure complete independence for the scientific investigators. While employed at the University of Birmingham MJAvT received funding from $\mathrm{O}_{2}$, Orange, T-Mobile, and Vodafone to carry out a feasibility study of health effects from radiofrequency exposure among employees of broadcasting and telecommunication industries.

Ethical approval: Multicentre research ethics committees for the south east and Scotland and all relevant local research ethics committees.

1 Cancer Research UK. www.cancerresearchuk.org/ (accessed 23 May 2005).

2 Sienkiewicz ZJ, Kowalczuk CI. A summary of recent reports on mobile phones and health (2000-2004). Didcot, Oxon: National Radiological Protection Board, 2005. (NRPBW65.)

3 Advisory Group on Non-ionising Radiation (AGNIR). Health effects from radiofrequency electromagnetic fields. Report of an advisory group on non-ionising radiation. Document of the NRPB 2003;14:1-177. www.hpa.org.uk/radiation/ publications/documents_of_nrpb/abstracts/absd14-2.htm (accessed 1 June 2005).

4 Inskip PD, Tarone RE, Hatch EE, Wilcosky TC, Shapiro WR, Selker RG, et al. Cellulartelephone use and brain tumors. N Engl J Med 2001;344:79-86.

5 Muscat JE, Malkin MG, Thompson S, Shore RE, Stellman SD, McRee D, et al. Handheld cellular telephone use and risk of brain cancer. JAMA 2000;284:3001-7.

6 Lonn S, Ahlbom A, Hall P, Feychting M, the Swedish Interphone Study Group. Longterm mobile phone use and brain tumor risk. Am J Epidemiol 2005;161:526-35.

Christensen HC, Schuz J, Kosteljanetz M, Poulsen HS, Boice JD, McLaughlin JK, et al. Cellular telephones and risk for brain tumours. Neurology 2005;64:1189-95.

8 Hardell L, Hansson Mild K, Carlberg M. Further aspects on cellular and cordless Hardell L, Hansson Mild K, Carlberg M. Further aspects
telephones and brain tumours. Int J Oncol 2003;22:399-407.

9 Hardell L, Carlberg M, Hansson Mild K. Use of cellular telephones and brain tumour risk in urban and rural areas. Occup Env Med 2005;62:390-4.

10 Auvinen A, Hietanen M, Luukkonen R, Kosela R-S. Brain tumors and salivary gland cancers among cellular telephone users. Epidemiology 2002;13:356-9.

11 Cardis E, Kilkenny M. International case-control study of adult brain, head and neck tumours: results of the feasibility study. Radiat Prot Dosimetry 1999;83:179-83.

12 World Health Organization. International classification of diseases for oncology. 3rd ed. Geneva: WHO, 2000.

13 Kleihues P, Cavenee WK. Pathology and genetics of tumours of the central nervous system.

14 Office of Population Censuses and Surveys. General practitioner morbidity statistics. Lon4 Office of Population
don: OPCS, 1992.

15 Lonn S, Forssen U, Vecchia P, Ahlbom A, Feychting M. Output power levels from mobile phones in different geographical areas; implications for exposure assessment. Occup Environ Med 2004;61:769-72.

16 Townsend P, Phillimore P, Beattie A. Health and deprivation:inequality and the north. New York: Croom Helm, 1988 .

17 Lonn S, Ahlbom A, Hall P, Feychting M. Mobile phone use and the risk of acoustic neuroma. Epidemiology 2004;15:653-9.

18 Johansen C, Boice J Jr, McLaughlin J, Olsen J. Cellular telephones and cancer-a nationwide cohort study in Denmark. J Natl Cancer Inst 2001;93:203-7.

19 Dimbylow P, Mann S. Characterisation of energy deposition in the head from cellular phones. Radiat Prot Dosimetry 1999;83:139-41.

20 Boice JD, McLaughlin JK. Epidemiologic studies of cellular telephones and cancer risk-a review. SSI Report. Stockholm: Swedish Radiation Protection Authority, 2002.

21 Rothman KJ. Epidemiological evidence on health risks of cellular phones. Lancet 2000;356:1837-40.

22 Parslow RC, Hepworth SJ, McKinney PA. Recall of past use of mobile phone handsets. Radiat Prot Dosimetry 2003;106:233-40.

23 Law GR, Smith AG, Roman E. The importance of full participation: lessons from a national case-control study. Br J Cancer 2002;86:350-5.

24 Habash RWY, Brodsky LM, Leiss W, Krewski D, Repacholi M. Health risks of electromagnetic fields. Part II: Evaluation and assessment of radio frequency radiation. Crit Rev Biomed Eng 2003;31:197-254.

25 Ahlbom A, Green A, Kheifets L, Savitz D, Swerdlow A. Epidemiology of health effects of radiofrequency exposure. Environ Health Perspect 2004;112:1741-54.

(Accepted 14 November 2005)

doi $10.1136 /$ bmj.38720.687975.55

Centre for Epidemiology and Biostatistics, Leeds Institute of Genetics, Health, and Therapeutics (LIGHT), Leeds LS2 9LN

Sarah J Hepworth medical statistician

Patricia A McKinney professor of paediatric epidemiology

Institute of Cancer Research, Section of Epidemiology, Sutton, Surrey SM2 5NG Minouk J Schoemaker medical statistician

Anthony J Swerdlow professor of epidemiology

Division of Epidemiology and Public Health, School of Community Health Sciences, Queen's Medical Centre, Nottingham NG7 2UH

Kenneth R Muir professor of epidemiology

Centre for Occupational and Environmental Health, Division of Epidemiology and Health Sciences, University of Manchester, Manchester M13 9PL

Martie J A van Tongeren senior lecturer in occupational and environmental health

Correspondence to: P A McKinney p.a.mckinney@leeds.ac.uk 